\title{
Unrepeatability of the Fuel Injection and Combustion Processes in the Diesel Engine Fuelled with Renewable Fuel
}

\author{
Wincenty Lotko'
}

\author{
1 Faculty of Mechanical Engineering, Kazimierz Pulaski University of Technology and Humanities in Radom, \\ Poland \\ e-mail: w.lotko@uthrad.pl
}

\begin{abstract}
Despite the fact that more than a hundred years have passed since the first design of the compression ignition (CI) engine appeared, its optimal design has not yet been achieved. It is still the subject of constant modernisation in order to meet the new expectations of users in terms of its dynamics, economy, and, in recent months, also ecology. The most effective fulfillment of these requirements is achieved through new solutions of the fuel supply system and electronic control of injection and combustion processes. The publication includes the test results obtained on the basis of two engines. One of them is the single-cylinder CI engine AVL5402, and the other one - a threecylinder CI engine AD3.152. The first one is equipped with the Common Rail fuel supply system, electronically controlled with the selenoid injector. The second engine has a CAV distributor fuel injection pump and traditional, mechanical controlled injectors. The paper demonstrates how these two different structural systems for supplying and controlling engine parameters affect the selected indicators of the injection and combustion process. The influence of diesel fuel (DF) and rapeseed oil (RO) feeding the engine in both different injection and control systems on the unrepeatibility of the injection pressure on the maximum combustion pressures in the engine cylinder and, consequently, non-uniformity of the crankshaft rotational movement of the engine were also pointed out. The continuation of the research in this area seems to be expedient. They can be supplemented with statistical models of these phenomena. The results obtained in this way could be helpful in optimising the design of power supply systems and engine combustion chambers.
\end{abstract}

Keywords: diesel engine, Common Rail, fuel injection, unrepeatability, alternative fuels

\section{INTRODUCTION}

Nowadays, very strict restrictions concerning the emissions of exhaust toxic components and the level of noise emitted by internal combustion engines are still encountered $[1,2]$. This forces the engine manufacturers to develop their designs continually. These development directions for compression-ignition engines are also stimulated by limited fuel resources. In recent decades, many countries have introduced new standards referring to the requirements for motor fuels, as well as new standards (changing annually), for the permissible content of limited, permissible toxic exhaust components and the level of limited noise. In compression ignition (CI) engines, this applies to oxides of nitrogen $\mathrm{NO}_{\mathrm{X}}$, hydrocarbons $(\mathrm{HC})$, carbon monoxide (CO) and particulates (PM).

Earlier diesel engine supply systems did not keep up with these tasks as far as high-speed engines are concerned, and it was necessary to optimise the control parameters (input and output) using the latest achievements in electronic control systems. It turned out that it was necessary to adjust the engine control parameters for each cylinder separately, rather than only for the first engine cylinder, like previously. The latest Common Rail fuel supply system attempts to meet such requirements.

The parameters of the fuel injection process significantly affect the combustion process in the cylinder, and consequently the engine power 
$[3,4]$. Every combustion engine, including CI engine is complicated as far as the adjustment is concerned. Hydraulic and pneumatic control systems, used so far, could not cope with the optimisation of control parameters concerning their tasks.

This refers to the power supply systems for the engines equipped with injection pumps, inline injection pumps, rotary injection pumps or pump injectors with spring injectors.

The essence of such an engine adjustment is to meet the requirements concerning environmental protection standards by optimising the correlation between the input and output parameters (or their characteristics) by means of using an integrated electronic control system. These parameters are controlled in a closed feedback loop, e.g. between the fuel and air, and the exhaust gas composition. This entire regulation and control system must result in achieving the assumed engine torque characteristics in a rotational speed function.

In the operation of the engine, it has been noticed that the phenomenon of the unrepeatability of the injection characteristics occurs in the fuel injection process, including clearly the maximum injection pressure from cycle to cycle [5 - 7]. This phenomenon is closely related to the hydrodynamic processes in the fuel supply system. The result of these phenomena is finally the combustion process in the engine chamber.

The permissible unevenness of the engine running depends on its purpose and in passenger car engines, the degree of non-uniformity is reported in the range of $1 / 40-1 / 50$ [8]. Under the engine operating conditions, its unevenness causes engine vibrations and noise [9].

The aim of the study was to determine the effect of two selected fuels: diesel and rapeseed oil on the unrepeatability of the selected parameters of the injection and the combustion process. It was also necessary to demonstrate the relationship between these parameters and the non-uniformity of the engine running.

In this work, $\mathrm{RO}$ was selected for tests since the physicochemical properties of this oil are significantly different in comparison to regular diesel fuel. RO represents renewable fuel for diesel engines. These fuels are stil investigated for different applications. Plant oils can be used as an environment friendly fuel. In this manner, blends of plant oils with diesel fuel and selected alcohols and ethers are also investigated [10-12].

\section{TEST SETUP, METHODOLOGY AND MATHERIALS}

For a detailed analysis of the unrepeatability phenomena of the injection and combustion processes, a single-cylinder engine from the AVL List $\mathrm{GmbH}$ in Graz, Austria was selected. It is prof. Hans List's recognised research centre. Professor Hans List also participates in the construction of new engines on behalf of car companies. The tested the AVL 5402 engine is equipped with a Common Rail fuel supply system. The basic technical parameters of this engine are given in Table 1.

The engine tests were carried out under stationary conditions of the engine work. The engine operated at 1200, 2200 and $3200 \mathrm{rpm}$ under torque of 7, 14 and $21 \mathrm{Nm}$. These conditions represent low, middle and high load of the AVL engine fuelled with both tested fuels.

Two types of fuels were used in this study. They are hydrocarbon fuels coming from oil refining: standard diesel fuel (DF) and second tested fuel comes from the group of vegetable fuels and it is rapeseed oil (RO). Unsaturated fatty acid esters of RO are used as diesel oil additives

Table 1. Engine characteristics [13, 14$]$

\begin{tabular}{|l|c|c|}
\hline Model & AVL 5402 & AD3.152 \\
\hline Type & direct injection & direct injection \\
\hline Number of cylinders & 1 & 2502 \\
\hline Displacement, $\mathrm{cm}^{3}$ & 511 & $91.44 / 127$ \\
\hline Bore/stroke, $\mathrm{mm}$ & $85.01 / 90.00$ & four stroke \\
\hline Cycle & four stroke & 16.5 \\
\hline Compression ratio & 17.5 & 35 \\
\hline Maximum Power, $\mathrm{kW}$ & 16 & 2250 \\
\hline Maximum speed, $\mathrm{rpm}$ & 4200 & CAV Distributor pump \\
\hline Injection pump & Common Rail & \\
\hline
\end{tabular}

The view of the test setup is shown in Fig. 1. 


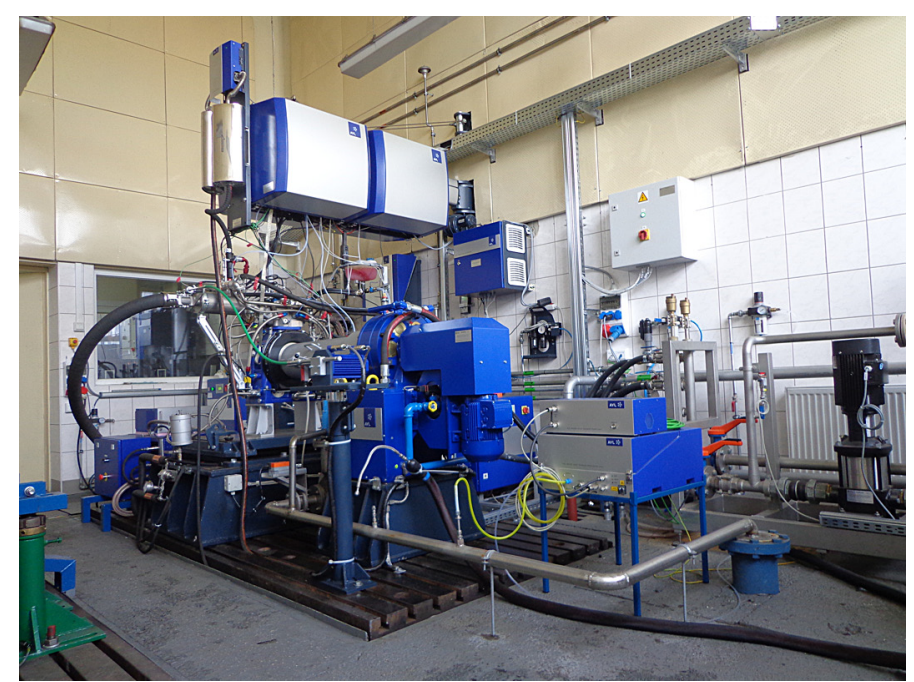

Fig. 1. General view of the AVL test bed

(FAME), in various volumes, in different countries. The basic physicochemical properties of these two fuels are given in Table 2.

In this paper, two parameters of the cycle-tocycle variations will be evaluated i.e.: maximum pressure of fuel injection $\mathrm{CVP}_{\text {inj }}$ and and maximum combustion pressure $\left(\mathrm{CV}_{\mathrm{Pc}}\right)$. A sample size for a finite population was used for the tests. The significance level is $\alpha=0.05$ and the permissible error $e=5 \%$. For the statistical analysis, 400 cycles recorded under the conditions specified above were taken into consideration. The standard deviation s for the population was determined by means of the formula (1):

$$
\begin{gathered}
\sigma=\sqrt{\frac{\sum_{i=1}^{k}\left(X_{i}-\bar{X}\right)^{2}}{k-1}} \\
k=\frac{z^{2} P(1-P)}{e^{2}}
\end{gathered}
$$

where: $P$ - fraction size, $z$-value from the cumulative distribution function of the normal distribution for the assumed materiality level,

$e-$ maximum estimation error,

$k$ - number of samples,

$X$ - tested parameter of unrepeatability.

\section{UNREPEATIBILITY OF FUEL INJECTION PRESSURE}

The injection system of the CI engine, due to the control process, should provide:

- correct course of injection characteristics,

- the required fuel amount throughout the entire engine operating range,

- even and repeatable distribution of fuel dose to all engine cylinders,

- the angle of the injection start in the whole range of engine operation,

- repeatable injection timing for each engine cylinder,

- constant pressure injector opening.

\begin{tabular}{|c|c|c|c|}
\hline \multirow{2}{*}{ Parameter } & \multirow{2}{*}{ Unit } & \multicolumn{2}{|c|}{ Fuel type } \\
\hline & & ON & OR \\
\hline Density at $15^{\circ} \mathrm{C}$ & $\mathrm{kg} / \mathrm{m}^{3}$ & 836.5 & 920.0 \\
\hline Kinematic viscosity at $40^{\circ} \mathrm{C}$ & $\mathrm{mm}^{2} / \mathrm{s}$ & 2.74 & 34.56 \\
\hline Surface tension $\times 10^{-2}$ & $\mathrm{~N} / \mathrm{m}$ & 3.71 & 3.38 \\
\hline Cetane number & - & 51.9 & 38.0 \\
\hline Specyfic energy & $\mathrm{MJ} / \mathrm{kg}$ & 43.8 & 36.9 \\
\hline Flash-point & ${ }^{\circ} \mathrm{C}$ & 62.0 & $>300$ \\
\hline Content FAME & $\%(v / v)$ & 7.0 & - \\
\hline
\end{tabular}

Table 2. Selected physicochemical properties of tested fuels 
One of the most important reasons for the unrepeatability of the CI engine cycles is the unrepeatability of the injection process (differences in fuel delivery) in subsequent cycles. Here, we deal with the nature of the stochastic process of atomising the fuel spectrum and the method of mixing fuel with air.

The injection systems using in-line injection pumps, distributor injection pumps, pump-injectors with spring injectors, due to the control of their mechanical elements (cams, springs), did not meet the expectations. That is why, the Common Rail fuel injection system with selenoid injectors controlled electronically was used in the research. The value of the maximum pressure was measured before the injector for the main fuel dose was used (Fig. 2).

The value of the fuel injection pressure unrepeatability indicator was determined from the formula (3):

$$
C V P_{i n j}=\frac{\sigma P_{i n}}{\overline{P_{i n}}}=\frac{\sqrt{\frac{1}{k-1} \sum_{i=1}^{k}\left[\left(P_{i n}\right)_{i}-\overline{P_{i n}}\right]^{2}}}{\overline{P_{i n}}}
$$

where: $\sigma P_{\text {in }}-$ standard deviation, $P_{i n}$ - average value of the injection pressure before the use of the injector for the main fuel dose,

$\left(P_{i n}\right)_{i}$ - pressure for $\mathrm{i}$ - this injection cycle, $k$ - the number of the analysed cycles equal to 400 .

The unrepeatability of the fuel injection process and the intake air results in the unrepeatability of the diagram of combustion pressure changes as a function of the crankshaft rotation angle. The most convenient measurable parameter characterising the combustion process in the engine is the pressure course in the fuction of the crankshaft rotation angle. Therefore, it can be considered as the unrepeatability indicator characterised by the difference between the maximum and mean indicated pressure. Differences in the maximum combustion pressure $[15,16]$ as a random variable was the criterion of the unrepeatability of subsequent engine operations cycles. The calculations according to the formula (3) of the maximum combustion pressure (Fig. 3) in the cylinder, marked as $\mathrm{CVP}_{c}$ should be made in the same way as determining the unrepeatability index of the maximum injection pressure.

\section{RESEARCH RESULTS}

\section{Unrepeatability of the fuel injection pressure}

The obtained results of the unrepeatability indicator of the injection pressure $\mathrm{P}_{\text {inj }}$ for the tested fuels i.e. DF and RO were shown in Fig. 4-6.

As it can be seen in Figure 4, the $\mathrm{CVP}_{\text {inj }}$ values are smaller than $0.02 \%$ for all measurement conditions. However, it is clear that the unrepeatable indicator is affected by rotational speed of the engine crankshaft as well as by the type of fuel burnt in the combustion chamber. The same observations are expressed in Figure 5.

Figure 6 confirms that $\mathrm{CVP}_{\text {inj }}$ indicator is strongly affected by the engine crankshaft speed. It can be stated that the unreapeatability of the injection process adequately grows for higher engine crankshaft speed. Moreover, it is visible that

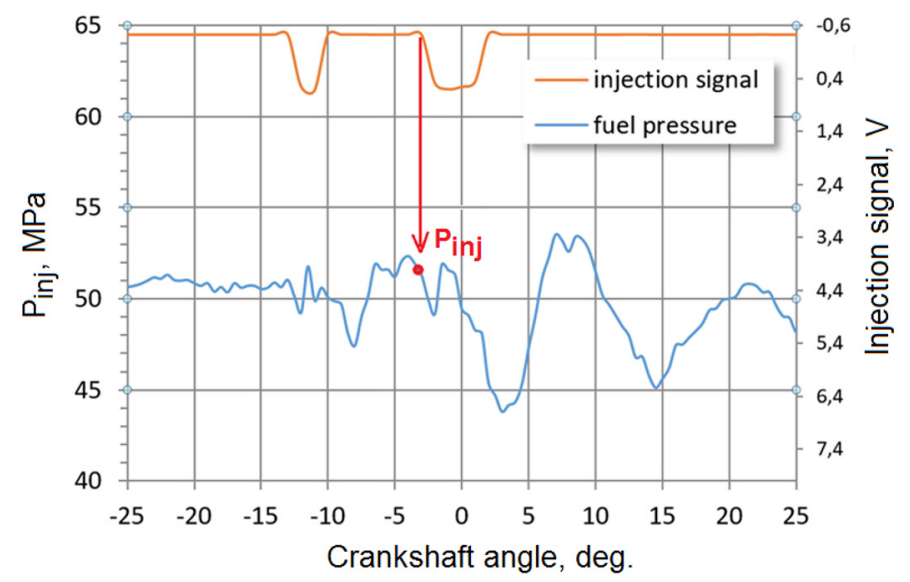

Fig. 2. Exemplary course of the fuel pressure before the injector was used in the AVL5402 engine with $\mathrm{P}_{\text {inj }}$ determination method 


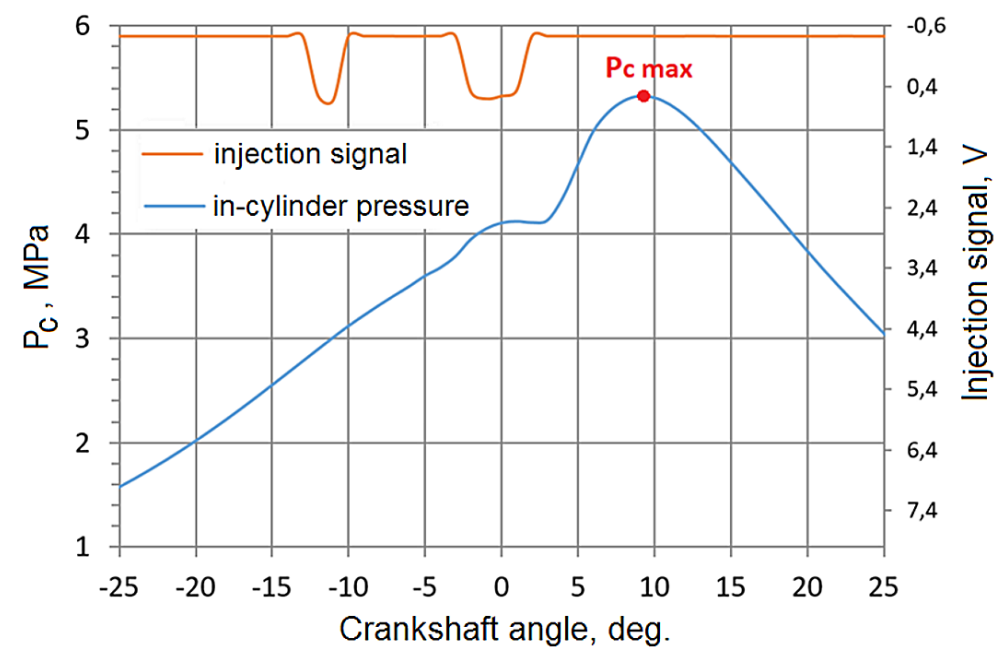

Fig. 3. Exemplary course of the combustion pressure in the cylinder of AVL 5402 engine with the maximum pressure $\mathrm{P}_{c \text { max }}$ marked

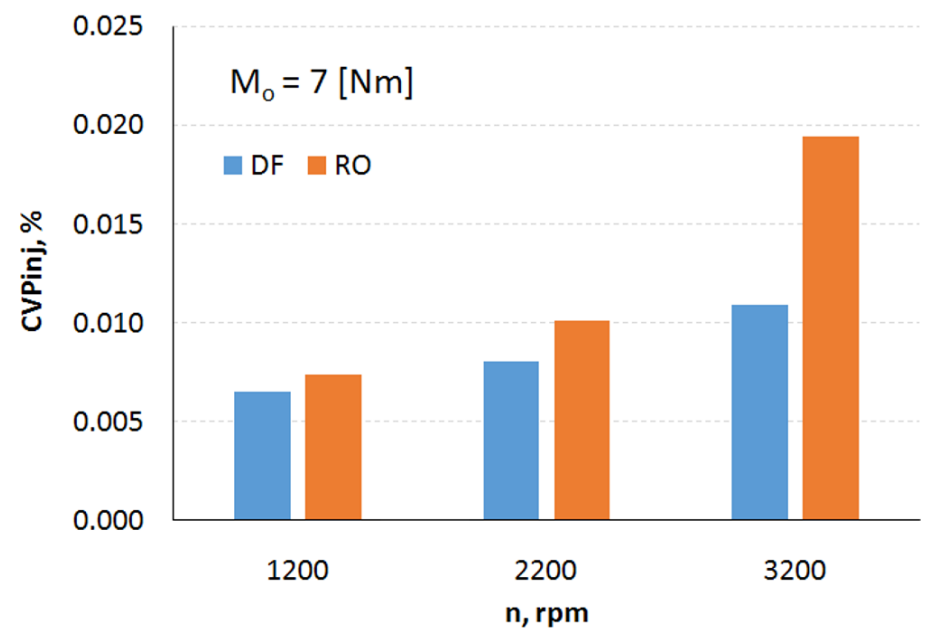

Fig. 4. $\mathrm{CVP}_{\text {inj }}$ values obtained for the AVL 5402 engine powered by DF and RO at torque at torque $7 \mathrm{Nm}$

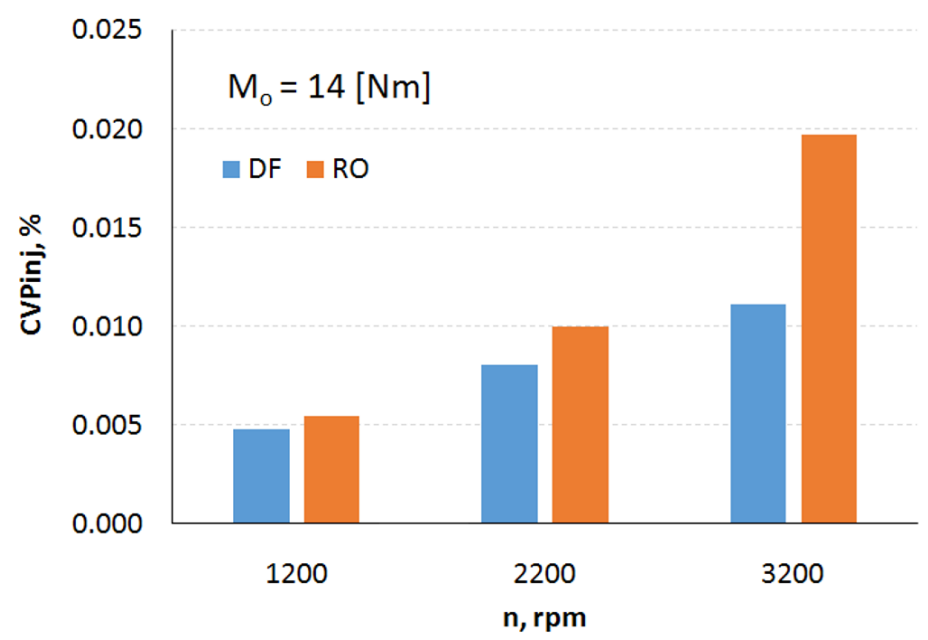

Fig. 5. $\mathrm{CVP}_{\text {inj }}$ values obtained for the AVL 5402 engine powered by DF and RO at torque $14 \mathrm{Nm}$ 


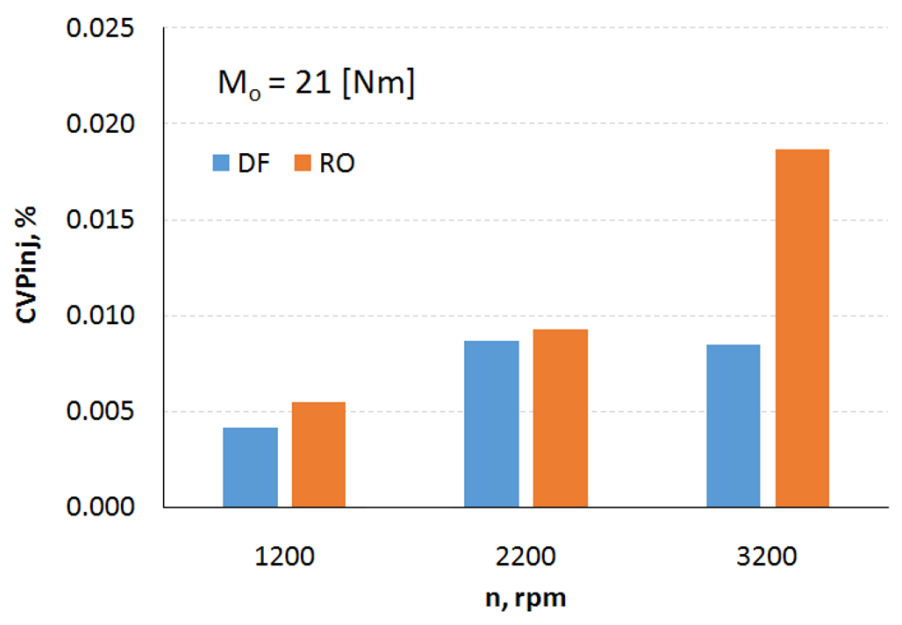

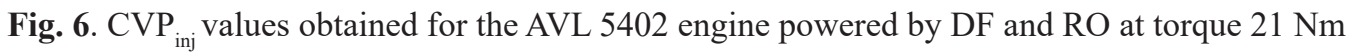

under such conditions the value of $\mathrm{CVP}_{\text {inj }}$ indicator is significantly higher for the engine fuelled with RO in comparison with DF.

\section{Unrepeatability of the combustion pressure}

The values of the $\mathrm{CVP}_{\mathrm{c}}$ unrepeatability indicator for the two tested fuels are shown in Figures 7-9. On the basis of the results expressed in these figures it can be stated that unrepeatability of the combustion process is affected mainly by the engine crankshaft rotational speed. For all measurement conditions, the $\mathrm{CVP}_{\mathrm{c}}$ values were lower than $2,5 \%$. It confirms that the combusition process is much more unrepeatable than the process of the fuel injection.

From Figures 7-9 it can be concluded that the kind of fuel burnt in the engine has a little impact on the unrepeatability of the combustion process. It was confirmed that the $\mathrm{CVP}_{\mathrm{c}}$ values are comparable for all measurement conditions expect of $2200 \mathrm{rpm}$ at $7 \mathrm{Nm}$.

The results presented in Fig. 7-9 confirm that the CVP value depends mainly on the engine crankshaft rotational speed. The values obtained at $3200 \mathrm{rpm}$ are twice higher in comparison with the results of the combustion unrepetablility typical for the engine operated at $1200 \mathrm{rpm}$.

The qualitative analysis of the obtained test results can be made on the basis of the data in Figures 4-9. It should be noted that the $\mathrm{CVP}_{\text {inj }}$ values are two orders of magnitude smaller in comparison to $\mathrm{CVP}_{\mathrm{c}}$, and in the AD3.152 engine both parameters have the same order of magnitude.

On the basis of the obtained results, it can be stated that the values of the $\mathrm{CVP}_{\mathrm{inj}}$ and $\mathrm{CVP}_{\mathrm{c}}$ indicators are influenced by:

a) engine speed. With its increase they achieve over fourfold lower values for the engine operation in relation to the speed $\mathrm{n}=1200 \mathrm{rpm}$

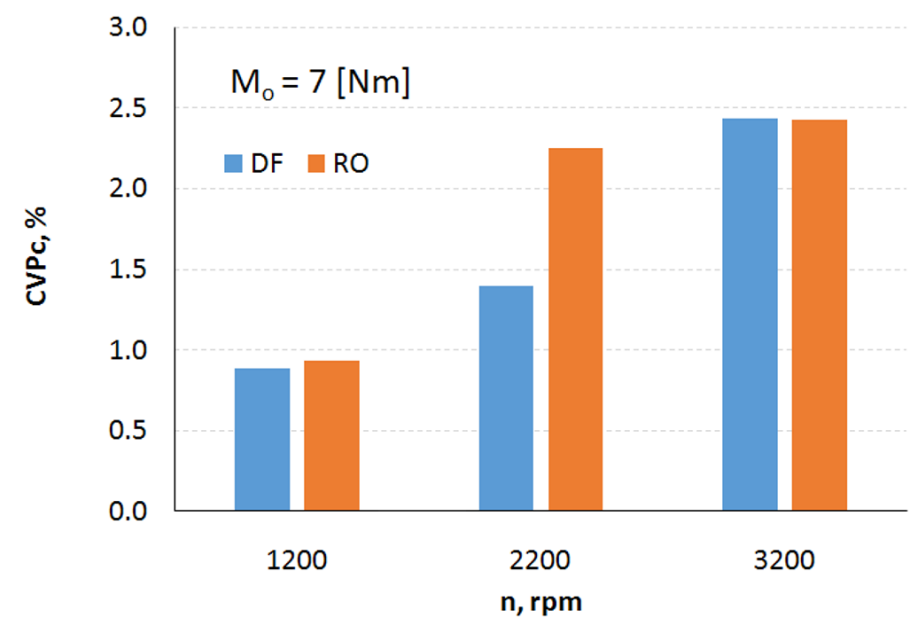

Fig. 7. $\mathrm{CVP}_{\mathrm{c}}$ values obtained for the AVL 5402 engine powered by DF and $\mathrm{RO}$ at torque $7 \mathrm{Nm}$ 


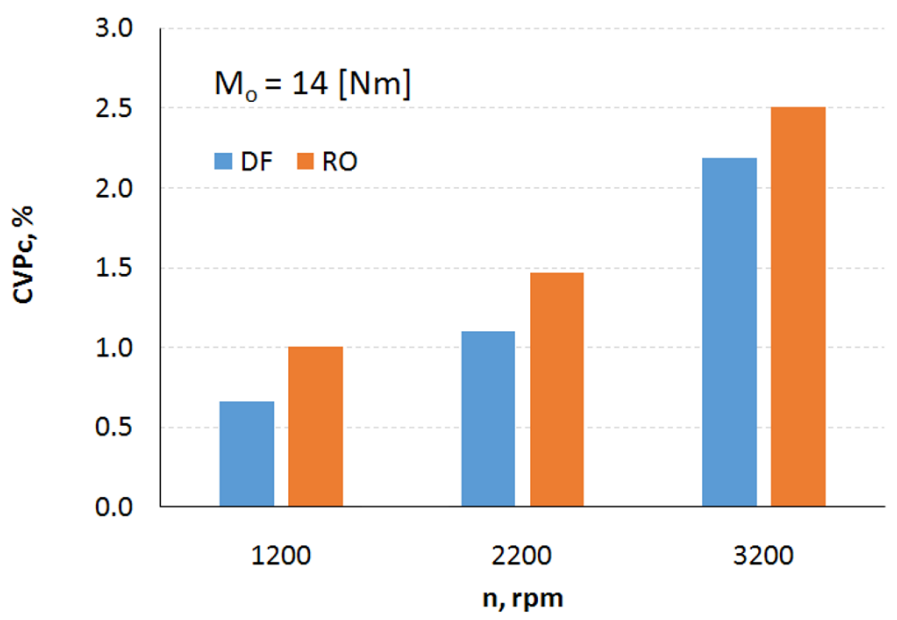

Fig. 8. CVP ${ }_{c}$ values obtained for the AVL 5402 engine powered by DF and RO at torque $14 \mathrm{Nm}$

for $\mathrm{RO}$, and for $\mathrm{DF}$ about twice lower values,

b) fuel density. With a higher density compared to

$\mathrm{DF}$, it can be assumed that the indicators $\mathrm{CVP}_{\text {inj }}$ and $\mathrm{CVP}_{\mathrm{c}}$ are higher depending on the engine speed,

c) in this case, the engine load has a little impact on the two analysed indicators; however, with a slightly larger impact on the $\mathrm{CVP}_{\text {inj }}$ indicator.

The CVP ${ }_{\text {inj }}$ indicator obtained for the AD3.152 engine equipped with a distributor injection pump and standard (spring) fuel injectors, mechanically controlled as well as Common Rail fuel system of AVL5402 engine, electronically controlled should also be referred to.

In the AVL 5402 engine, the $\mathrm{CVP}_{\mathrm{c}}$ indicator achieves most favourable values for the engine operation at the speed of $\mathrm{n}=1200 \mathrm{rpm}$, and almost three times higher and less favourable at the speed of $\mathrm{n}=3200 \mathrm{rpm}$.
As far as the CVP indicator of the AVL5402 engine is concerned, the least undesirable effect on the non-uniformity of the engine crankshaft movement is affected by its work as far as its high totational speeds and and maximum engine loads are concerned.

On the basis of the result analysis for $\mathrm{CVP}_{\text {inj }}$ and CVP for different rotational speeds of the AVL 5402 engine, it is clearly seen that the increase in the $\mathrm{CVP}_{\text {inj }}$ parameter also results in worse $\mathrm{CVP}_{\mathrm{c}}$ parameters from cycle-to-cycle.

The use of high-pressure fuel feed pump in the AVL 5402 engine, regardless of the engine speed, resulted in the separation of the fuel delivery function from the injection parameter control. In this way, the following precise and repeatable parameters of the injection process were provided: the injection start, the injection timing, fuel dose and the injection pressure. As a result, the opening of the injector was made independent of the pressure in the container.

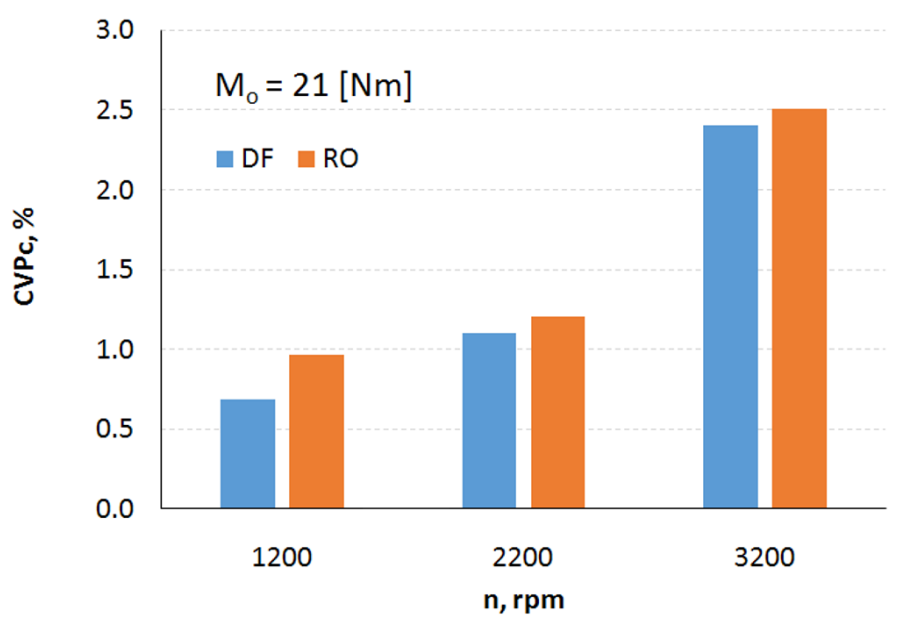

Fig. 9. $\mathrm{CVP}_{\mathrm{c}}$ values obtained for the AVL 5402 engine powered by DF and RO at torque $21 \mathrm{Nm}$ 
As for the AD3.152 engine with a CAV distributor injection pump at its full load, the indicator $\mathrm{CVP}_{\text {inj }}$ for $\mathrm{DF}$ was obtained in the range $0.90-1.10 \%$, and the indicator $\mathrm{CVP}_{\mathrm{c}}: 1.15-2.0 \%$. Like for the AVL 5402 engine, they were also higher for RO. The changes in these indicators were also similar for the AVL5402 engine.

It was also found that the values $\mathrm{CVP}_{\text {inj }}$ of the AD3.152 engine were two orders of magnitude higher than for the AVL5402 engine, and the parameter $\mathrm{CVP}_{\mathrm{c}}$ had a similar scale, although the values were lower at low and medium engine speeds.

The injection and combustion parameters controlled by mechanical elements additionally cause their changes along the vehicle mileage.

The preliminary comparison of $\mathrm{CVP}_{\text {inj }}$ indicator shows that the fuel supply system in the AVL 5402 engine is more repeatable. These numerical comparisons indicate that it is at least two orders of magnitude more beneficial than for the AD3.152 engine. This has a significant impact on the parameters of the combustion process in the engine and consequently, for example, on the emissions of limited toxic components of exhaust fumes, fuel consumption, etc.

\section{Injection and Combustion Process in Terms of Uneven Engine Running}

As a result of the unrepeatability of the injection process phenomenon, and consequently the combustion process we are deal with the variability of engine torque over time. As a rule, this applies to the engine operation under transient conditions [5], but also under stable conditions (without accelerations and decelerations). Under stable engine conditions, its torque, during one revolution of the crankshaft, changes to a certain extent. As a result, the angular velocity of the engine crankshaft is not constant and thus, the movement of the engine crankshaft is characterised by uneven engine running.

In order to improve the unevenness of the engine running, a flywheel is mounted at the end of the crankshaft. In road vehicle engines with multi-cylinder engines, the flywheel is mainly used to maintain its uniformity for idle speed. The variability of the crankshaft rotational speed is determined by the degree of unevenness of the engine running - the degree of the flywheel unevenness according to the formula (4) can be expressed as follows:

$$
\delta=\frac{\omega_{\max }-\omega_{\min }}{\omega_{a v}}
$$

where: $\omega$ - angular speed of the crankshaft, respectively: max, average, min.

The parameters determining the engine suitability include, among others, such indicators as:

- the average effective pressure and specific fuel consumption,

- combustion pressure increase rate,

- maximum combustion pressure,

- maximum temperature in the combustion chamber,

- the content of limited toxic components in exhaust gases,

- engine noise.

The high efficiency of the CI engine depends, to a large extent, on the quality of mixing the fuel with air, with the right volume of fuel dose and the amount of air in the combustion chamber. Two factors influence the way the mixture is produced in a CI engine. They provide the required dose of the fuel in a timely manner and its precise atomisation in the cylinder, as well as the appropriate amount of air with the required degree of turbulence. Thus, the engine designer can have an impact on the preparation of the appropriate macro and microstructure combustible mixture owing to the fuel and air supply system. The stable idle speed of car and tractor engines falls within the range of 500-800 rpm.

The engine crankshaft, due to its shape as well as the method of support and loading with variable pressure forces in the combustion chamber, the inertia forces arising as a result of acceleration and deceleration of the crank system masses, is particularly susceptible to vibrations and resilience. The inertia forces originate from the movement of the crank system and their size depends on the rotational speed of the engine, the size of the masses involved in reciprocating and rotary motion, the crank radius of the crankshaft as well as the length of the connecting rod. Due to the non-uniform motion of the piston, these forces vary depending on its position. Periodically varying cylinder gas pressure and inertia forces occurring in the engine cause the crankshaft to undergo torsional, bending and longitudinal vibrations. The torsional vibrations are particularly dangerous in the operation process, and in extreme cases they can lead to the 
destruction of the crankshaft as a result of the fatigue damage to the material structure.

A higher unrepeatability indicator of the combustion pressure in the engine cylinder also causes an increase in the non-uniformity of the engine running. Greater elastic vibrations of the engine crankshaft are the result. In consequence, they may cause an increase in the torsional vibrations dangerous for the the engine crankshaft. The damages to the engine crankshaft usually cause its complete destruction.

There is a change in torque over time in the reciprocating IC engines. This phenomenon occurs not only under its transient operating conditions, but also under stable conditions when the torque changes during one revolution of the engine crankshaft [5]. As a result, the angular speed of the crankshaft is non-uniform, and the rotational speed of the crankshaft is characterised by irregularities within acceptable limits.

The engine is protected by a flywheel against such operating conditions. Its task is to store surplus energy transferred to the crankshaft during the operation of cylinders during acceleration of its rotational movement and then release stored energy when there is its shortage or outage.

\section{CONCLUSIONS}

The introduction of distributor pumps had a number of operational advantages, such as distinction between the functions of pumping and distributing fuel, which prevented leaks in the pump, and, what is very important, eliminated the decrease of high pressure in the pump.

On the basis of the results from the analysis of the AD3 engine, 152 with CAV pump and AVL 5402 engine with Common Rail injection system, it can be clearly seen that the $\mathrm{CVP}_{\text {inj }}$ and $\mathrm{CVP}_{\mathrm{c}}$ indicators are more beneficial when supplying the engine with a storage injection system. With some simplification, it can be assumed that the nature of the change $\mathrm{CVP}_{\text {inj }}$ is comparable to the change of CVP. As a consequence, the engine crankshaft is less exposed to lower maximum fast-changing gas pressures in the cylinder. The result is, among other things, lesser non-uniformity in the rotational movement of the engine crankshaft.

For multi-cylinder engines, due to the torsional vibrations of the crankshaft and the resulting distortions of indicator charts, the $\mathrm{CVP}_{\mathrm{c}}$ indicators are more reliable than the average pressure indicated for the analysis of the combustion process. The analysis of the selected statistical indicators carried out earlier showed that there were some relationships between the physicochemical properties of the tested fuels, engine load and its rotational speed. It seems advisable to continue the research in this area and perform such statistical analyses for the engines that best meet their requirements as far as their dynamics, ecology and economy are concerned. It is possible that the statistical models of these phenomena and the results obtained from the future research could be used to optimise the design of engine power supply systems and combustion chambers. The analysis of the cycle-to-cycle pressure oscillations may be also helpful to control the performance of the engine [17]. Moreover, to reduce the cost of the research on the issues presented in the publication, extensive work has been carried out on shaping phenomena of injection and combustion processes in compression-ignition engines.

The issues of the stochastic process of atomising and mixing fuel with air in the engine cylinder have not yet been sufficiently recognised. They require further research to determine their impact on the uniqueness of the subsequent engine cycles.

\section{REFERENCES}

1. Bielaczyc P., Woodburn J. Trends in Automotive Emission Legislation: Impact on LD Engine Development, Fuels, Lubricants and Test Methods: a Global View, with a Focus on WLTP and RDE Regulations. Emission Control Science and Technology, 5, 2019, 86-98.

2. Bielaczyc P., Woodburn J., Gandyk M. Trends in automotive emissions, fuels, lubricants, legislation and test methods - a global view, with a focus on the EU and US - summary of the 5th International Exhaust Emissions Symposium (IEES). Combustion Engine. 166(3), 2016, 78-82.

3. Bai F., Zhang Z., Du Y., Zhang F., Peng Z. Effects of Injection Rate Profile on Combustion Process and Emissions in a Diesel Engine. Journal of Combustion. 2017, 1-8.

4. Suh H.K. Study on the twin-pilot-injection strategies for thereduction in the exhaust emissions in a low-compression-ratioengine. Journal of Automobile Engineering. 228, 3, 335-343.

5. Lotko W., Górski K., Longwic R. Nieustalone stany pracy silnika wysokoprężnego zasilanego olejem napędowym $\mathrm{z}$ eterem-etylo tert butylowym. 
Wydawnictwo Komunikacji i Łączności, 2010.

6. Schmillen K., Wolschendorf J. Cycle - to - Cyle Variations of Combustion Noise in Diesel Engines. SAE Transactions. 98(3), 1989, 60-70.

7. Wajand J.A. Wtrysk paliwa-czasowa i geometryczna niepowtarzalność przebiegu. Automotive Technology. 2, 1981.

8. Wajand J.T., Wajand J.A. Tłokowe silniki spalinowe. Wydawnictwo Naukowo Techniczne, 1993.

9. Heywood J.B. Internal Combustion Engine Fundamentals. New York, Mc Graw Hil, 2018.

10. Górski K., Smigins R. Selected physicochemical properties of diethyl ether/rapeseed oil blends and their impact on diesel engine smoke opacity. Energy Fuels. 32(2), 2018, 1796-1803.

11. Górski K., Przedlacki M. Evolution of the influence of Diethy Ether (DEE) addition on selected physicochemical properties of diesel oil and ignition delay period. Energy and Fuels. 28(4), 2014, 2608-2616.

12. Tutak W., Jamrozik A., Pyrc M., Sobiepański M. A comparative study of co-combustion process of diesel-ethanol and biodiesel-ethanol blends in the direct injection diesel engine. Applied Thermal Engineering. 117, 2017, 155-163.

13. Longwic R., Lotko W. Analiza wpływu sztywności sprężyn zaworów tłoczących pompy wtryskowej na wybrane parametry procesu spalania w silniku o zapłonie samoczynny. Archiwum Motoryzacj. 1,2001 .

14. Górski K. Experimental Investigation of Diesel Engine Powered with Fuel Microemulsion. Advances in Science and Technology Research Journal. 14(2), 2020, 41-48.

15. Kowalewicz A. Systemy spalania szybkoobrotowych tłokowych silników soalinowych. Wydawnictwo Komunikacji i Łączności, 1990.

16. Kowalewicz A. Fundamentals of combustion processes. Wydawnictwo Naukowo Techniczne, 2000.

17. Sen A.K., Rafal Longwic R., Litak G., Górski K. Analysis of cycle-to-cycle pressure oscillations in a diesel engine. Mechanical Systems and Signal Processing. 22, 2008, 362-373. 